\title{
Electrochemical advanced oxidation technologies for removal of organic pollutants from water
}

\author{
Mehmet A. Oturan
}

Received: 20 March 2014 / Accepted: 25 March 2014 / Published online: 11 April 2014

(C) Springer-Verlag Berlin Heidelberg 2014

Improving or maintaining the quality of freshwater constitutes one of the challenges of modern society. Freshwater resources are exposed to a large amount of high number of synthetic organic pollutants such as industrial chemicals, pesticides, dyes, and pharmaceuticals and personal care products that are released daily into natural water system via direct discharge of wastewater. Most of these pollutants are persistent organics and refractory to the conventional water/wastewater treatment techniques and pass through sewage treatment plants partial modified or unmodified. Contamination of the environment and especially of surface and ground water by toxic/persistent pollutants became special concern because water quality has a great impact on the well-being of human and also of all the living beings, since certain pollutants have capacity, even in very small concentration, to drastically harm living organisms. Therefore, the protection of the available resources by prevention strategy and the control of their quality are regarded as important issues of the current century. The prevention becomes the most important action regarding the protection of natural water resources. Effective protection of natural water resources is possible only through treatment of wastewater effluents before their injection into natural water bodies. Therefore, the development of effective, economically, and ecologically compatible treatment processes is of great importance.

To remove toxic and biorecalcitrant organic pollutants from water, treatment techniques based on a powerful oxidant, namely hydroxyl radicals $(\mathrm{OH})$, are developed during last decades. These techniques are commonly called "advanced oxidation processes" (AOPs) (Glaze et al., 1987; Pignatello

\section{Responsible editor: Philippe Garrigues}

\section{A. Oturan $(\bowtie)$}

Université Paris-Est Marne-la-Vallée, 5, Boulevard Descartes, Champs-sur-Marne 77454, Marne-la-Vallée, France

e-mail: Mehmet.Oturan@univ-paris-est.fr et al., 2006; Oturan and Aaron, 2014). Among these techniques, electrochemical advanced oxidation processes have proved to have high efficiency with advantages such as versatility, high energy efficiency, amenability of automation, and safety because it operates at mild conditions with limited use of chemicals (Brillas et al., 2009; Panizza et al., 2009; Sires and Brillas, 2012; Feng et al., 2013).

This special issue ELECTROX of Environmental Science and Pollution Research has been designed and prepared in the context of the use of environmentally friendly processes for a better protection for our planet. It is devoted to offer an overview on the latest development breakthroughs and advances in advanced electrochemical technology for removal of persistent organic pollutants from water with both application and implication perspectives. It covers a wide range of environmental electrochemistry-related processes for removal of toxic and biorefractory organic pollutants from water, including processes like electro-Fenton, anodic oxidation, photoelectro-Fenton, sonoelectro-Fenton, peroxielectrocoagulation, electrochemical peroxidation, photoassisted Fered-Fenton, and related techniques, with the use of new anode/cathode materials, catalysts, and process coupling in order to investigate the oxidative degradation/mineralization kinetics and mechanisms as well as removal efficiencies. Therefore, I think, this special issue will provide a reference document in the area of environmentally friendly water treatment technologies based on electrochemical advanced oxidation processes for removing of persistent organic pollutants from water/wastewater and stimulating researchers to be aware of how electrochemistry might contribute to efforts to achieve a sustainable and clean environment.

The special issue ELECTROX collects 24 original contributions written by internationally renowned experts from different countries. More than 80 authors from 14 countries contributed to 24 papers accepted for this special issue: Brazil (3), China (5), France (8), India (2), Iran (2), Italy (5), Korea 
(1), Mexico (2), Portugal (1), Romania (1), Tunisia (1), Spain (5), Turkey (2), and USA (2), including 2 extensive reviews, 3 mini-reviews, and 19 research articles. The first paper of this special issue is an extensive review on the EAOPs that has been developed for the prevention and remediation of environmental pollution, especially focusing on water streams. It is a contribution of four worldwide best research groups (Prof. E. Brillas and Dr. I. Sirés, Universitat de Barcelona, Spain; Prof. M.A. Rodrigo, Universidad de Castilla-La Mancha Spain; Dr. M. Panizza, University of Genoa, Italy; and Prof. M.A. Oturan, Université Paris-Est, France) in the field of electrochemical advanced oxidation processes. This review article encloses heterogeneous processes like anodic oxidation and photoelectrocatalysis methods, in which hydroxyl radicals are generated at the anode surface either electrochemically or photochemically and homogeneous methods like electroFenton, photoelectro-Fenton photoelectrocatalysis, and sonoelectrolysis, in which hydroxyl radicals are produced in the solution bulk. This paper presents a general overview on the application of EAOPs to the removal of aqueous organic pollutants, firstly reviewing the most recent works and then looking to the future. A global perspective on the fundamentals and experimental setup is offered, and lab- and pilot-scale experiments are examined and discussed. The second review article is from the research team of Prof. Oturan and reports the coupling of electrochemical advanced oxidation and biological processes in order to enhance the effectiveness of treatment and reduce energy cost. Three mini-review papers bring latest developments on different aspects of the special applications of EAOPs. Concerning the research papers, most of them report the feasibility and performance of boron-doped diamond (BDD) thin-film anode in anodic oxidation of organic pollutants like dyes, pharmaceuticals and industrial wastewaters. Also, a large number of research papers are devoted to efficient removal of organic pollutants from water by electro-Fenton process using different anode (Pt, DSA, BDD) and cathode (carbon-felt or gas diffusion) and to investigate the kinetics, intermediate products, and mineralization pathway. Other papers are dedicated to other interesting aspects of EAOPs or their coupling with other methods like the use of zero-valent iron as heterogeneous catalyst in electroFenton process (Zhang et al., Nankai University, China), the use of electro-Fenton process to improve biodegradability for a biological treatment (Ferrag-Siagh et al., Université de Rennes 1, France), photo-assisted Fered-Fenton process to remove COD from landfill leached (Wu et al., Wuhan University, China) and coupling of electrochemical oxidation and adsorption for the treatment of dye wastewater (Bouaziz et al., Université de Toulouse, France).

The aim of this special issue ELECTROX with publications of high-quality contributions is to show to environmental engineers and chemist researchers that EAOPs can help to solve water contamination problems. Therefore, I would like to thank all the authors and reviewers for their valuable contribution to this special issue. Firstly, I wish to express my sincere thanks to the authors for their outstanding work. All papers published in this issue have been accepted after a rigorous peer review process. Accordingly, I think, this special issue is widely informative and will be greatly beneficial to the readers of this journal and researchers working in the field of electrochemical advanced oxidation processes for a clean and safe environment.

I am indebted to Dr. Philippe Garrigues, the Editor-in-Chief of Environmental Science and Pollution Research for his enthusiastic reception, assistance, and opportunity to publish this special issue. I also sincerely thank Emmanuelle PignardPéguet, Editorial assistant for her professional assistance during the preparation and editing of this special issue. I believe that this special issue ELECTROX constitutes reference material for the future progress of the environmental electrochemistry.

\section{References}

Brillas E, Sirés I, Oturan MA (2009) Electro-Fenton process and related electrochemical technologies based on Fenton's reaction chemistry. Chem Rev 109: 6570-6631. doi: doi:10.1021/cr900136g

Feng L, van Hullebusch ED, Rodrigo MA, Esposito G, Oturan MA (2013) Removal of residual anti-inflammatory and analgesic pharmaceuticals from aqueous systems by advanced oxidation processes. A review. Chem Eng J 228:944-964. doi:10.1016/j.cej.2013.05.061

Glaze WH, Kang JW, Chapin DH (1987) The chemistry of watertreatment processes involving ozone, hydrogen-peroxide and ultraviolet-radiation. Ozone-Sci Eng 9:335-352

Oturan MA, Aaron JJ (2014) Advanced oxidation processes in water/ wastewater treatment: Principles and applications. A review. Crit Rev Env Sci Tec (in press). doi: 10.1080/10643389.2013.829765

Panizza M, Cerisola G (2009) Direct and mediated anodic oxidation of organic pollutants. Chem Rev 109:6541-6569. doi:10.1021/ cr9001319

Pignatello JJ, Oliveros E, MacKay A (2006) Advanced oxidation processes for organic contaminant destruction based on the Fenton reaction and related chemistry. Crit Rev Env Sci Tec 36:1-84. doi: $10.1080 / 10643380500326564$

Sirés I, Brillas E (2012) Remediation of water pollution caused by pharmaceutical residues based on electrochemical separation and degradation technologies: A review. Environ Int 40:212-229. doi: 10.1016/j.envint.2011.07.012 


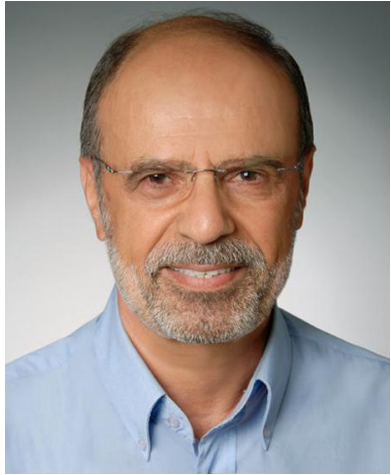

Mehmet A. Oturan was born in Tunceli, Turkey, in 1950. He obtained Chemical Engineer degree in 1973, MS degree in 1975, and his Ph.D. degree in Analytical Electrochemistry under the supervision of Prof. A. Yildiz in 1979 at the Hacettepe University in Ankara before becoming associate professor at the same university. He undertook a postdoctoral stay in 1981 to complete his studies in electrochemistry at the Université Paris VII-Denis Diderot under supervision of Prof. J. M. Savéant in the field of organic electrochemistry. From 1982 to 1989 , he worked as contracted lecturer-researcher at the Université Paris VIIDenis Diderot and researcher in pharmaceutical industry. In 1989, he joined the newly formed Université de Marne-la-Vallée as associate professor. There, he developed the electro-Fenton process in its "carbon-felt cathode" version. After obtaining his HDR (ability to supervise researchers) degree in 1997, he became full professor at the Université de
Marne-la-Vallée (currently Université Paris-Est) in 2002. At present, he is headmaster of the Département de Géomatériaux at the Institut Francilien des Sciences Appliquées (IFSA), head of the Laboratoire Géomatériaux et Environnement (LGE), leader of the Environmental Chemistry research group, head of the master Géo-Environnement, and vice president of the French group of pesticides. He is also a member of National University Council ( $31^{\text {st }}$ section) board member of Scientific Council of Université Paris-Est Marne-la-Vallée, and board member of Doctoral Scholl SIE (Science, Engineering, and Environment) of Université Paris-Est. His research activities mainly focus on the generation of radical species in a catalytic way by means of electrochemical, chemical, or photochemical techniques and its use in environmental chemistry including AOPs, chemical kinetics and mechanisms, and electrochemical engineering. He has been associate editor of the Journal of Environment Engineering and Monitoring from 2006 to 2010. He serves as editor of Sustainable Environmental Research and as associate editor of Environmental Chemistry Letters. He is a member of editorial board of several scientific journals. He has supervised $35 \mathrm{Ph}$.D. theses, published more than 150 peer-reviewed papers (with more than 3,500 Citations and $\mathrm{H}$ factor 35 according to Web of Science), three books, and seven book chapters and presented more than 200 contributions, including 50 invited conferences to scientific national and international congresses. 